ENCYCLOPEEDIE Encyclopédie berbère

BERBERE

22 | 2000

22 | Hadrumetum - Hidjaba

\title{
Hétéroclisie linguistique
}

S. Chaker

\section{OpenEdition}

Journals

Édition électronique

URL : http://journals.openedition.org/encyclopedieberbere/1727

DOI : 10.4000/encyclopedieberbere.1727

ISSN : 2262-7197

\section{Éditeur}

Peeters Publishers

\section{Édition imprimée}

Date de publication : 1 janvier 2000

Pagination : 3454-3455

ISBN : 2-7449-0127-X

ISSN : 1015-7344

\section{Référence électronique}

S. Chaker, « Hétéroclisie linguistique », Encyclopédie berbère [En ligne], 22 | 2000, document H45, mis en ligne le 01 juin 2011, consulté le 25 septembre 2020. URL : http://journals.openedition.org/ encyclopedieberbere/1727 ; DOI : https://doi.org/10.4000/encyclopedieberbere.1727

Ce document a été généré automatiquement le 25 septembre 2020

(c) Tous droits réservés 


\section{Hétéroclisie linguistique}

\section{S. Chaker}

1 Caractéristique d'un mot "hétéroclite", c'est-à-dire dont la flexion est composite et empruntée à plusieurs thème" (Marouzeau, p. 100) ou dont "le paradigme flexionnel est emprunté à plusieurs racines" (Dubois, p. 243).

2 Cette notion de la grammaire traditionnelle rend compte de toute une série d'anomalies lexicales en berbère, en particulier pour les noms référant à des êtres vivants sexués. Dans ces champs lexico-sémantiques, on constate que, très souvent, les formes du masculin et du féminin ou, plus rarement, du singulier et du pluriel, ne sont pas construites sur les mêmes bases lexicales ; cette hétérogénéité est même quasiment de règle pour les grands mammifères. Ainsi :

argaz "homme" mais tamețtut "femme" (et non targazt)

ales "homme" mais midden "hommes" (touareg)

tamețtut mais tilawin, ou tisednan etc. (et non timețțuyin)

akrar/ikerri "mouton" mais tiүsi/tixsi "brebis"

tixsi "brebis" mais ulli "brebis" (ovins)

tafunast "vache" mais tistan/tisita "vaches"

3 Hétérogénéité des bases lexicales d'autant plus remarquable en berbère que les oppositions de genre et de nombre ont normalement un caractère très systématique ; ainsi sur le thème nominal myar "personne âgée" :

amyar "vieux" tamyart "vieille"

imyaren "vieux" (plur.) timyarin "vieilles"

4 Cette situation a évidemment une explication diachronique: des racines lexicales distinctes ont été utilisées pour dénommer des réalités apparentées parce que, culturellement ou fonctionnellement, elles n'avaient pas le même statut; puis les formes ont été confondues en un paradigme unique. L'hétéroclisie, dans ces domaines de pratiques sociales (dénominations des êtres humains, animaux domestiques, etc.) est donc un indice intéressant de l'histoire culturelle (cf. Chaker, 1995).

5 Le phénomène peut également se rencontrer dans les paradigmes verbaux (comme en français pour le verbe aller : all-, ir-, va-) mais il est beaucoup plus rare. Un cas largement attesté est celui du verbe ini "dire", dont le thème d'aoriste intensif est, dans de 
nombreux dialectes berbères, construit sur le thème qqar, issu de yer "crier, appeler" (bien que la forme régulière ttini soit également bien attestée). Dans ce cas, il peut s'agir de confusion par contiguïté sémantique : "dire/parler intensivement/habituellement" se confondant avec "crier/appeler" ou de nécessités locales d'évitement d'une forme ambiguë ou socialement dépréciée ; pour le cas du kabyle, on peut penser à la proximité entre ttini "dire (intensif)" et ttinit "éprouver des envies (de femme enceinte)"! Parfois, l'hétérogénéité du paradigme est d'origine clairement phonétique, comme en touareg où le thème d'intensif de enn "dire" est ganna ; il ne s'agit pas là d'un cas d'hétérocli-sie, mais de la conservation, dans le thème d'intensif d'une forme ancienne et plus complète de la racine $\left(^{*} G N[x]\right.$ ou $\left.Y N[x]\right)$.

\section{BIBLIOGRAPHIE}

BASSET A., La langue berbère. Morphologie. Le verbe, Étude de thèmes, Paris, 1929.

BASSET A., La langue berbère, 1952, Londres (1969).

CHAKER S., Textes en linguistique berbère (Introduction au domaine berbère), Paris, CNRS, 1984.

CHAKER S., Linguistique berbère : études de syntaxe et de diochronie, Louvain/Paris, Editions Peeters, 1995.

CHAKER S., Linguistique et préhistoire : autour de quelques noms d'animaux domestiques en berbère, L'homme méditerranéen. Mélanges offerts à Gabriel Camps, Publications de l'Université de Provence, Aix, p. 259-264.

DUBOIS J. et al, Dictionnaire de linguistique, 1972, Paris, Larousse.

MAROUZEAU J., Lexique de la terminologie linguistique, Paris, Geuthner, 1969.

MOUNIN G., Dictionnaire de la linguistique, Paris, PUF, 1974.

INDEX

Mots-clés : Linguistique 